Boletín de la Sociedad Geológica Mexicana

VOLUMEN 68, NÚM. 1, 2016, P. 11-21

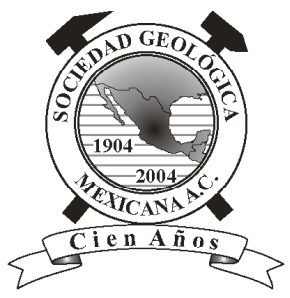

\title{
The Dolichopodidae (Diptera) of Mexican amber
}

\author{
Daniel J. Bickel ${ }^{1}$, Monica M. Solórzano Kraemer ${ }^{2}$ \\ ${ }^{1}$ Entomology Section, Australian Museum, 6 College Street, Sydney NSW 2000 Australia. \\ ${ }^{2}$ Senckenberg Forschungsinstitut und Naturmuseum, Senckenberganlage 25, 60325 Frankfurt am Main, Germany. \\ *danb@austmus.gov.au
}

\begin{abstract}
The family Dolichopodidae (Diptera) from Mexican Chiapas amber are reviewed. Six new species are described: Mesorhaga pseudolacrymans, Amblypsilopus monicae, Medetera totolapa, Medetera amissa, Peloropeodes paleomexicana and Neoparentia chiapensis. All genera are currently extant in the modern Mesoamerican fauna, and three of the new species can be closely associated with modern species groups or species. This suggests that many elements of the modern Neotropical dolichopodid fauna have been in place since the Miocene.
\end{abstract}

Keywords: Miocene, Dolichopodidae, Mesorhaga, Amblypsilopus, Medetera, Peloropeodes, Neoparentia, new species, Mexico.

\section{Resumen}

La familia Dolichopodidae (Diptera) en el ámbar Mexicano de Chiapas es analizada. Se describen seis nuevas species: $\underline{\text { Mesorhaga }}$ pseudolacrymans, Amblypsilopus monicae, Medetera totolapa, Medetera amissa, Peloropeodes paleomexicana y Neoparentia chiapensis. Todos los géneros existen actualmente en la fauna mesoamericana moderna, y tres de las nuevas especies pueden estar estrechamente relacionadas con grupos o especies modernas. Esto sugiere que muchos elementos de la fauna moderna de dolichopodidos neotropicales han estado presentes desde el Mioceno.

Palabras clave: Mioceno, Dolichopodidae, Mesorhaga, Amblypsilopus, Medetera, Peloropeodes, Neoparentia, species nuevas, México.

\section{Introduction}

Mexican amber from the state of Chiapas is considered to be of Middle Miocene age (some 15 - 20 mya) and derived from the fossilized resin of the tree species Hymenaea mexicana (Fabaceae) (Poinar and Brown, 2002). The reconstruction of the Mexican amber forest shows it to be close to modern lowland tropical forest, especially to mangrove formation (Langenheim, 1967; Solórzano Kraemer, 2007). A sizable number of arthropod inclusions have been found in this amber, reviewed in Solórzano Kraemer $(2007,2010)$. Here it might be noted that the better-known Dominican Republic amber is of similar age, and also derived from a Hymenaea species, H. protera (Poinar, 1991).

The Dolichopodidae (long-legged flies) are one of the largest families within the order Diptera, and comprise more than 7500 described species in some 200 genera. In Central America more than 400 species are already reported (Bickel, 2009). Dolichopodidae are often abundant in warm mesic habitats. The family is common in Cenozoic amber inclusions, primarily because adults of many genera live on tree trunks where they both hunt for small arthropod prey and search for mates. This behavior makes them likely to become entrapped in sticky resin flows, and ultimately 
included in amber.

This study is based on 37 inclusions containing Dolichopodidae. The pieces are from two different Mexican amber deposits: Simojovel de Allende and Totolapa in the state of Chiapas. Form this material six species are newly described.

\section{Materials and Methods}

Institutional material cited in this work use these following acronyms (also see Table 1):

(SMF) - Senckenberg Forschungsinstitut und Naturmuseum, Frankfurt am Main, Germany.

(SMNS) - Staatliches Museum für Naturkunde, Stuttgart, Germany.

(UCMP)- University of California Museum of Paleontology, Berkeley, California, U.S.A.

Many Mexican amber inclusions show signs of lateral shearing, where specimens appear "stretched." This is probably the result the amber being subjected to geological stress with heat and pressure while embedded in the surround matrix.

Many of the inclusions, especially from UCMP and SMNS have been so trimmed that they comprise tiny pieces enclosed by only the thinnest layer of amber. Although this makes the inclusions readily visible, it does not protect them from degradation of the surrounding amber. As a result, many pieces, especially in the UCMP collection, have become darkened and obscured over time, preventing any clear view. We have subsequently embedded valuable specimens within clear casting resin, both for ease of viewing and protection from further darkening.

The descriptions use standard entomological terminology, and follow McAlpine (1981), and a noted below. In describing the hypopygium, 'dorsal' and 'ventral' refer to morphological position prior to genitalic rotation and flexion. Thus, in figures showing a lateral view of the hypopygium, the top of the page is morphologically ventral, while the bottom is dorsal. The $\mathrm{CuAx}$ ratio is the length of the m-cu crossvein/ distal section $\mathrm{CuA}$. The position of features on elongate structures such as leg segments is given as a fraction of the total length, starting from the base. The relative lengths of the podomeres should be regarded as representative ratios and not measurements. The ratios for each leg are given in the following formula and punctuation: trochanter + femur; tibia; tarsomere 1/ 2/ 3/ 4/ 5. The following abbreviations and terms are used: MSSC - Male secondary sexual character(s), non-genitalic characters found only on the male body; I, II, III: pro- , meso-, metathoracic legs; C, coxa; T, tibia; F, femur; ac, acrostichal setae; ad, anterodorsal; av, anteroventral; dc, dorsocentral setae; dv, dorsoventral; pd, posterodorsal; pv, posteroventral; $\mathrm{t}$, tarsus; $\mathrm{t} 1-5$, tarsomeres 1 to 5 .

\section{Taxonomy}

The following descriptions discuss species placement and cite appropriate references. For further taxonomic information and a generic key for the identification of Mexican amber dolichopodid inclusions, see Bickel (2009) in the Manual of Central American Diptera.

\section{Subfamily SCIAPODINAE}

\section{Genus MESORHAGA Schiner}

Remarks. Mesorhaga is a cohesive, well defined, cosmopolitan genus recognized by a combination of the distinctive overall habitus, venation, and highly derived male postabdomen (Bickel, 1994). The Mesoamerican fauna comprises some 11 species and was recently revised (Bickel, 2007).

\section{Mesorhaga pseudolacrymans Bickel, sp. n.}

Type material. Amber specimens from Simojovel, Chiapas, Mexico. Holotype, ô, \#Mx360 (Fig. 1a-b); paratype $\hat{\jmath}$, \# Mx19 (SMNS).

Description. Male: body length: $3.6 \mathrm{~mm}$; wing: $3.2 \mathrm{x}$ $1.6 \mathrm{~mm}$ (Fig. 1a).

Head: two strong postvertical setae present, continuation of postocular row; weaker but distinct proclinate vertical seta on lateral frons; pair strong diverging ocellar setae on prominent ocellar tubercle; vertex, frons, face, and clypeus dark metallic blue green; clypeus narrowed distally; of eyes; palp dark brown with black apical seta; proboscis dark brown; antenna black; pedicel with some long ventral setae; $1^{\text {st }}$ flagellomere subrectangular; arista dorsal, bare, and about as long as head height; ventral postcranium with abundant white hairs.

Thorax: metallic green with bronze reflections; apparently 3 pairs ac setae; 5 strong dc present, decreasing in size slightly anteriorly; 1 posterior supra-alar seta, 2 post-sutural intra-alar setae; 1 presutural intra-alar seta, 1 postpronotal seta, 2 notopleural setae, subequal; lateral scutellar setae about one half length of median scutellar setae; propleuron without setae.

Legs: all coxae and remainder of legs dark brown to black; CI and CII with black anteriolateral setae; CIII with strong black lateral seta at $1 / 2$ and some shorter setae; tarsome 5 on all legs slightly expanded with claws projecting laterally; I: $3.2 ; 3.7 ; 1.8 / 0.8 / 0.4 / 0.3 / 0.3$; FI ventrally base; TI bare major setae; II: 4.1; 5.0; 3.5/ 1.2/ 0.8/ 0.4/ 0.4; FII with some long slender av and pv setae; TII bare of major setae except for subapical circlet of setae, short pd and ad seta and strong apical ventral seta; III: 4.5; 5.3; 2.2/ 1.9/ $1.0 / 0.5 / 0.3$; FIII with some long slender av and pv setae; TIII with av and pv row of short curved setae.

Wing: with brown cloud over basal and anterior part of the wing, extending posteriad of $\mathrm{CuA}$ and beyond the bend in vein $\mathrm{M}$, but with posterior wing margin hyaline; vein 
The Dolichopodidae (Diptera) of Mexican amber

Table 1. Mexican amber inclusions of Dolichopodidae (Diptera).

\begin{tabular}{|c|c|c|c|c|c|c|}
\hline Subfamily & Genus & Species & Sex & Specimen & Collection & Deposit \\
\hline Diaphorinae & Chrysotus & sp. & female & 13026 & UCMP & Simojovel \\
\hline Diaphorinae? & & & female & B-8414-32 & UCMP & Simojovel \\
\hline Diaphorinae? & & & female & 13004 & UCMP & Simojovel \\
\hline Dolichopodinae & Hercostomus? & sp. & female & 12955 & UCMP & Simojovel \\
\hline Medeterinae & Medetera & amissa n. sp. & male & 12961 & UCMP & Simojovel \\
\hline Medeterinae & Medetera & sp. & female & 12956 & UCMP & Simojovel \\
\hline Medeterinae & Medetera & sp. & female & 12763 & UCMP & Simojovel \\
\hline Medeterinae & Medetera & totolapa $\mathrm{n} . \mathrm{sp}$. & 2 males & SMF Be 2511 & SFMK & Totolapa \\
\hline Medeterinae & Systenus & sp. (damaged) & female & SMF Be 2512 & SMFK & Totolapa \\
\hline Medeterinae & & & female & Mx 226 & SMNS & Simojovel \\
\hline Peloropeodinae & Peloropeodes & paleomexicana $\mathrm{n}$. sp. & male & B-8425-151 & UCMP & Simojovel \\
\hline Sciapodinae & Amblypsilopus & monicae $\mathrm{n} . \mathrm{sp}$. & male & Mx 254 & SMNS & Simojovel \\
\hline Sciapodinae & Amblypsilopus & sp. & 2 females & Mx 228 & SMNS & Simojovel \\
\hline Sciapodinae & Amblypsilopus & sp. & female & Mx 261 & SMNS & Simojovel \\
\hline Sciapodinae & Amblypsilopus & sp. & female & Mx 281 & SMNS & Simojovel \\
\hline Sciapodinae & Amblypsilopus & sp. & female & Mx 374 & SMNS & Simojovel \\
\hline Sciapodinae & Amblypsilopus & sp. & female & Mx 378 & SMNS & Simojovel \\
\hline Sciapodinae & Amblypsilopus & sp. & female & Mx 384 & SMNS & Simojovel \\
\hline Sciapodinae & Amblypsilopus & sp. & female & Mx 318 & SMNS & Simojovel \\
\hline Sciapodinae & Mesorhaga & pseudolacrymans n. sp. & male & Mx 19 & SMNS & Simojovel \\
\hline Sciapodinae & Mesorhaga & pseudolacrymans n. $\mathrm{sp}$. & male & Mx 360 & SMNS & Simojovel \\
\hline Sympycninae & Neoparentia & chiapensis n. sp. & & Mx 210 & SMNS & Simojovel \\
\hline Sympycninae & & & female & Mx 228 & SMNS & Simojovel \\
\hline Sympycninae & & & male & 123007 & UCMP & Simojovel \\
\hline Sympycninae? & & & male & Mx 232 & SMNS & Simojovel \\
\hline obscured/damaged & & & & 1 piece & SMNS & Simojovel \\
\hline obscured/damaged & & & & 11 pieces & UCMP & Simojovel \\
\hline
\end{tabular}

$\mathrm{R}_{4+5}$ with gentle arched curve in distal wing; $\mathrm{M}$ with gentle right angle curve at $1 / 3$ between $\mathrm{dm}$ cu crossvein and wing apex, to join costa just anteriad of apex; crossvein $\mathrm{dm}$ cu straight; $\mathrm{CuAx}$ ratio: 1.2; lower calypter dark brown with black rim and fan of black setae; halter stalk dark brown, club brownish.

Abdomen: mostly dark metallic green; male tergite 1 with posterolateral row of long setae (MSSC); tergites 4-5 with long black ventral setae near lateral margins; sternite 8 with long setae; hypopygium (Fig. 1b) black; epandrium elongate and cylindrical; hypandrium and phallus arising near of epandrium; hypandrium tapering, narrow, and symmetrical, phallus long and narrow; epandrial lobe broadly ovate, with strong setae on inner margin at $1 / 2$ and 3/4; surstylus comprising 34 short overlapping arms; cercus stout and curved, with strong basolateral setae, and 
with apex distally expanded with some apical indentations.

Female: unknown.

Remarks. Mesorhaga pseudolacrymans is known from two inclusions in Chiapas amber, and is placed in the lacrymans species group, as defined in Bickel (2007). This group comprises four recent species found in low to mid-elevation forests from Costa Rica to Peru. They all share the following characteristics: 1) first flagellomere subrectangular with dorsal arista;2) males and females with brown infuscation over most of the wing (synapomorphy) - this is clearly visible in Fig. 1a; 3) vein $M$ with an almost right angle bend between crossvein $\mathrm{dm}-\mathrm{cu}$ and the wing apex, and 4) males often with dark coloured halters. Mesorhaga pseudolacrymans displays all these characters, in addition to having similar podomere rations as modern M. lacrymans, and clearly belongs in this species group.

Etymology. This species' name reflects its similarity to the extant species Medetera lacrymans.

\section{Genus AMBLYPSILOPUS Bigot}

Remarks. Amblypsilopus is a rich and complex pantropical genus. Adults of many species can sometimes be found resting on tree trunks. In addition to the new species below based on the only male, some seven inclusions were found with females only (e.g., Fig. 1f). The genus is discussed extensively in Bickel (1994).

Amblypsilopus monicae Bickel, sp. n.

Type material. Amber specimens from Simojovel, Chiapas, Mexico. Holotype, Ô, \#Mx254, Figs 1c-e) (SMNS).

Description. Male. Length $3.4 \mathrm{~mm}$; wing 3.5 x 1.0 (Fig. 1c)

Head: (Fig. 1e) occiput deeply excavated between ocellar tubercle; distinct postvertical seta present, slightly converging; pair strong diverging ocellar setae present; vertical setae slightly proclinate and converging; frons, face and clypeus metallic blue-green; face/ clypeus tapering slightly ventrally; palp yellowish with 2 black setae; proboscis apparently dark brown; first flagellomere subrectangular but tapering distally; arista dorsoapical.

Thorax: mostly green with bronze reflections, with dusting of silvery pruinosity on mesonotum, metepimeron dark green; 3 pairs long ac; 2 strong posterior dc, with 4 weak setae anteriad (MSSC); scutellum with pair of strong median setae and short weak lateral setae

Legs: CI, trochanters and remainder of legs yellow, with only distalmost tarsomeres infuscated; CII and CIII dark metallic brown; CI and CII with pale anterior hairs; CIII with black lateral at $1 / 3 ; \mathrm{I}: 4.2 ; 4.7 ; 5.0 / 1.7 / 1.0 / 0.7 / 0.4$; TI with black ad seta at $1 / 8$, otherwise leg bare of major setae; II: 4.8; 7.5; 6.0/ 2.0/ 1.6/ 0.9/ 0.5; FII bare of major setae; TII with short ad at $1 / 8$, and covered with short almost erect setae (MSSC?); IIt1 also with short setae, and with 5 longer ventral setae along length; III: 5.7; 8.3; 4.8/ 1.9/ 1.1/
$0.7 / 0.4$; FIII with short subapical av and pv seta; TIII with ad at $1 / 5$, with some 5-6 spaced dorsal setae along distal two-thirds, and with apical ad seta.

Wing: hyaline; anal lobe present; costa unmodified; $\mathrm{R}_{4+5}$ with flexion before joining apex anteriad of apex; vein $M$ gradually diverging from $R_{4+5}$ from base, and halfway between $\mathrm{dm}$-cu crossvein, vein M1 braches and arches towards $\mathrm{R}_{4+5}$, veins becoming subparallel, and M1 also joining margin anteriad of apex; crossvein dm-cu slightly sinuate; $\mathrm{CuAx}$ ratio: 2.5 ; lower calypter yellow with fan of yellowish setae; halter yellow.

Abdomen: tergite 1 yellow with narrow metallic green posterior band and a pair of strong posterolateral seta; tergites 2-5 mostly yellow anteriorly and laterally, with metallic blue-green posterior band, and each with posterior row of some 4 strong black setae; tergites 6-7 mostly metallic green; hypopygium (Fig. 1d) mostly dark brown with yellow cercus; hypandrium arising from base of epandrium and with left lateral arm; phallus elongate; pedunculate elongate epandrial lobe present with apical setae; surstylus distally expanded rounded with short dorsal finger like arm; cercus elongate, digitiform and extending beyond surstylar apex.

Female. Unknown.

Remarks. Amblypsilopus monicae is known from a single male, but additional female Amblypsilopus species in the material examined may represent this species (see Table 1). A. monicae has many features found in recent Neotropical congeners (e.g., A. mexicanus (Aldrich) and $A$. variegatus (Loew)), such as long, mostly yellow legs, male legs usually without major setation but with short semierect hairs, abdominal tergites often yellow with metallic green posterior bands, and the hypopgyium with expanded surstylus and simple cercus.

Etymology. This species is named in honor of Monica M. Solórzano Kraemer, the principal researcher on Chiapas amber inclusions.

\section{Subfamily MEDETERINAE}

This subfamily includes many genera that characteristically associated with tree trunks, making them likely to become entrapped in tree resin flows, later to become amber inclusions. Apart from the species-rich genus Medetera, Mexican amber also has a representative of the genus Systenus Loew (see Fig. 2g), whose larvae are known to inhabit moist tree holes.

\section{Genus MEDETERA Fischer von Waldheim}

Remarks. Adults of this cosmopolitan genus are commonly found resting vertical surfaces such as tree trunks. The larvae of some Holarctic species feed on scolytid bark beetle larvae within their galleries, and are therefore important predators of these forest pests. 

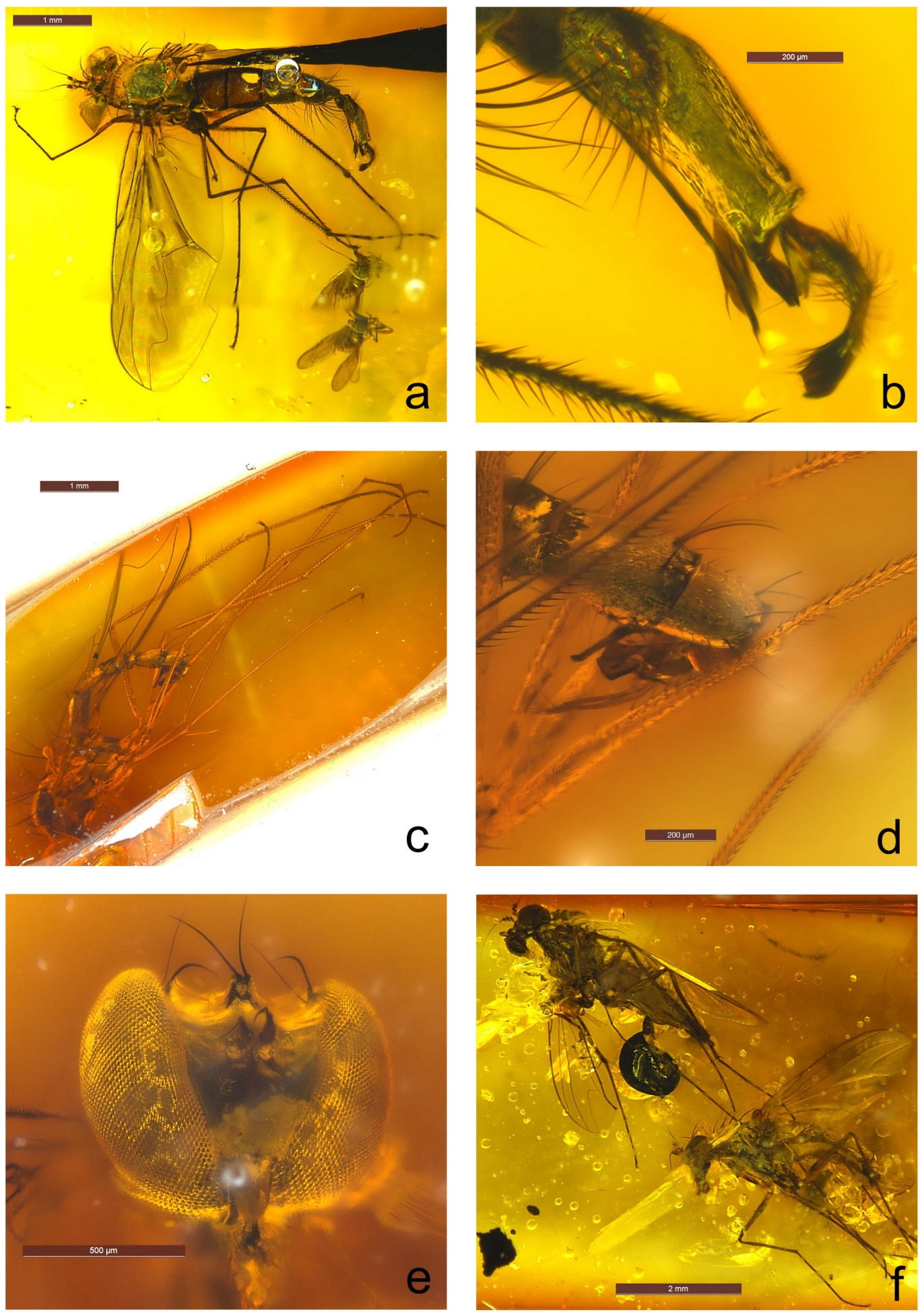

Figure 1. Mesorhaga pseudolacrymans, sp. n.: a. male habitus, dorsal (note ventral image refraction); b. hypopygium, left lateral. Amblypsilopus monicae sp. n.: c. male habitus, left lateral; d. hypopygium, left lateral; e. male head, anterior. Amblypsilopus spp.: f. two females, habitus.

Medetera amissa Bickel, n. sp.

Type material. Amber specimen from Simojovel, Chiapas, Mexico. Holotype, ô, \#12961, Figs 2c-f, (UCMP).
Description. Male: $2.4 \mathrm{~mm}$; wing: $2.2 \mathrm{~mm}$. (Fig. 2c)

Head: dorsal postcranium concave; frons, face and clypeus dark metallic blue-green; setae black; strong vertical 
and ocellar setae present; face only slightly narrowed below antennae, and sides subparallel along length; clypeus distinct; eye with facets uniform; palp black, ovate, with black apical seta; proboscis dark brown; antenna black; first flagellomere rounded, subrectangular; arista apical, and slightly longer than head height.

Thorax: (fig. 2d) metallic blue-green with bronze reflections; posterior mesonotum distinctly flattened and slightly depressed; setae black; dense field of short setulae across anterior mesonotum; ac short, biseriate to mesonotal depression; 3 strong dc setae, with anteriormost dc short and indistinguishable from anterior mesonotal field of setulae; 1 posterior supra-alar seta, 2 post-sutural intra-alar setae, with posterior seta almost twice length of anterior seta; 2 presutural intra-alar seta, 1 long upcurved postpronotal seta, subtended but short pale seta, 2 notopleural setae, with anterior twice length of posterior, and 1 proepisternal setae above CI; scutellum with well-developed median and lateral setae, lateral two thirds length of median.

Legs: coxae mostly dark brown with metallic green reflections, but yellowish near apex; trochanters and remainder of legs yellow, but distalmost tarsomeres brownish; CI and CII with short white setae on anterior surface, and CII with stronger seta anterolaterally; CIII with single strong white lateral seta in basal third; legs covered with short whitish vestiture; I: $2.5 ; 3.1 ; 1.0 / 0.5 ; 0.8 / 0.4 / 0.4$; FI without major setae; TI with white apicoventral seta; It $_{2}$ and $\mathrm{It}_{3}$ flattened, and curved, forming "hood"; $\mathrm{It}_{2}$ spatulate, expanded distally, and $\mathrm{It}_{3}$ expanded laterally and with deep rounded excavation along anterior margin of distal half (Fig. 2e) (all MSSC); II: 3.0; 3.0; 1.9/ 0.9/ 0.7/ 0.4/ 0.3; FII bare of major setae but with ventral row of white hairs; TII with strong ad-pd setal pair at $1 / 4$ with ad seta stronger, strong subapical ventral seta, and shorter subapical setae present; III: $3.4 ; 4.2 ; 1.1 / 1.7 / 1.0 / 0.6 /$ distal tarsomere missing; FIII slightly swollen, but without strong anterior setae (often found on aberrans Group species); TIII bare of discernible major setae, but with distinct black apicoventral flattened toothlike projection over IIIt . $_{1}$ (MSSC).

Wing: not visible in plan view; halter pale yellow.

Abdomen: metallic green with some bronze reflections; tergites 1-5 with short black vestiture, and setae along posterior margins; hypopygium (Fig. 2f); basally dark brown, and with expanded yellow surstylus, and yellow cercus; epandrium elongate, subrectangular; hypandrium arising at mid-length, and forming hood over phallus; surstylus narrow, deeply cleft, apically upcurved and slightly expanded with some setae; cercus mostly concealed between with surstyli.

Female. Unknown.

Remarks. Medetera amissa is known from a single, slightly sheared male from Mexican amber. It is clearly a member of the aberrans species group as defined here: thorax metallic green, little obscured by pruinosity; field of short setulae extending across anterior mesonotum; dorsal arm of surstylus strongly produced apically, ventral arm reduced to subtending lobe; males often with flattened, modified tarsomeres on leg I. The aberrans species group has a recent pan-tropical distribution with greatest diversity in the Neotropical region.

Medetera amissa can be identified by the distinctive modified male tarsus I, where $\mathrm{It}_{2}$ is spatulate and expanded distally, and $\mathrm{It}_{3}$ is expanded laterally and with a deep rounded excavation along the distal anterior margin (Fig. 2e). For further information on the aberrans group, see Bickel and Arnaud, 2011).

Etymology. The specific epithet is from the Latin word amissus, meaning "lost," as the piece was in a UCMP loan assumed to be lost, but subsequently found.

\section{Medetera totolapa Bickel, n. sp.}

Type material. Amber specimen from Totolapa, Chiapas, Mexico. Holotype, đ̊, paratype đ̊ SMF Be 2511, SMF Be 2512, Figs 2a-b (SMF).

Description. Male. Length $2.4 \mathrm{~mm}$; wing $2.3 \times 0.7$ (Fig. 2a)

Head: dorsal postcranium concave; frons, face and clypeus dark metallic blue-green; setae black; proclinate and converging vertical and strong diverging ocellar setae present; face only slightly narrowed below antennae, and sides subparallel along length; clypeus distinct; eye with facets uniform; palp black, ovate, with black apical seta; proboscis dark brown; antenna brown; pedicel with only rather short setae; first flagellomere short rounded; arista apical slightly longer than head height; dorsalmost postorbital setae bordering vertex black, but remaining postorbitals white, and longer on ventral half; lower postcranium with some long white setae.

Thorax: dark brown with metallic green reflections; posterior mesonotum distinctly flattened and slightly depressed; setae black; without dense field of setulae across anterior mesonotum, ac short biseriate, some 10 pairs; 5 strong dc setae present, decreasing in size anteriorly; 1 posterior supra-alar seta, 2 post-sutural intra-alar setae, with posterior seta long almost twice length of anterior seta; 2 presutural intra-alar seta, 1 postpronotal seta, 2 notopleural setae, subequal; scutellum with well-developed median setae, with lateral setae reduced to tiny hairs.

Legs: coxae mostly dark brown with metallic green reflections and femora dark brown; CI and CII with short brownish anterior setae; CIII with strong black lateral seta near $1 / 2$; I: $2.9 ; 2.3 ; 1.0 / 0.8 / 0.6 / 0.3 / 0.4$; leg I without major setae and unmodified; II: $3.2 ; 3.5 ; 1.5 / 1.2 / 0.0 / 0.7 /$ 0.3 ; FII bare; TII with ad-pd setal pair near $1 / 5$ and with subapical ventral seta; III: 4.0; 4.2; 0.8/1.4/ 0.9/ 0.5/ 0.5; FIII bare; TIII with ad setae at $1 / 4$ and subapically, and some short dorsal setae along distal half.

Wing: hyaline; $\mathrm{R}_{2+3}$ joining costa at $7 / 8 ; \mathrm{R}_{4+5}$ and $\mathrm{M}$ diverging to level of dm-cu crossvein, then converging to become subparallel in distal fifth of wing, both ending near wing apex; $\mathrm{CuAx}$ ratio: 0.5; lower calypter pale yellow with fan of brownish setae; halter yellow. 

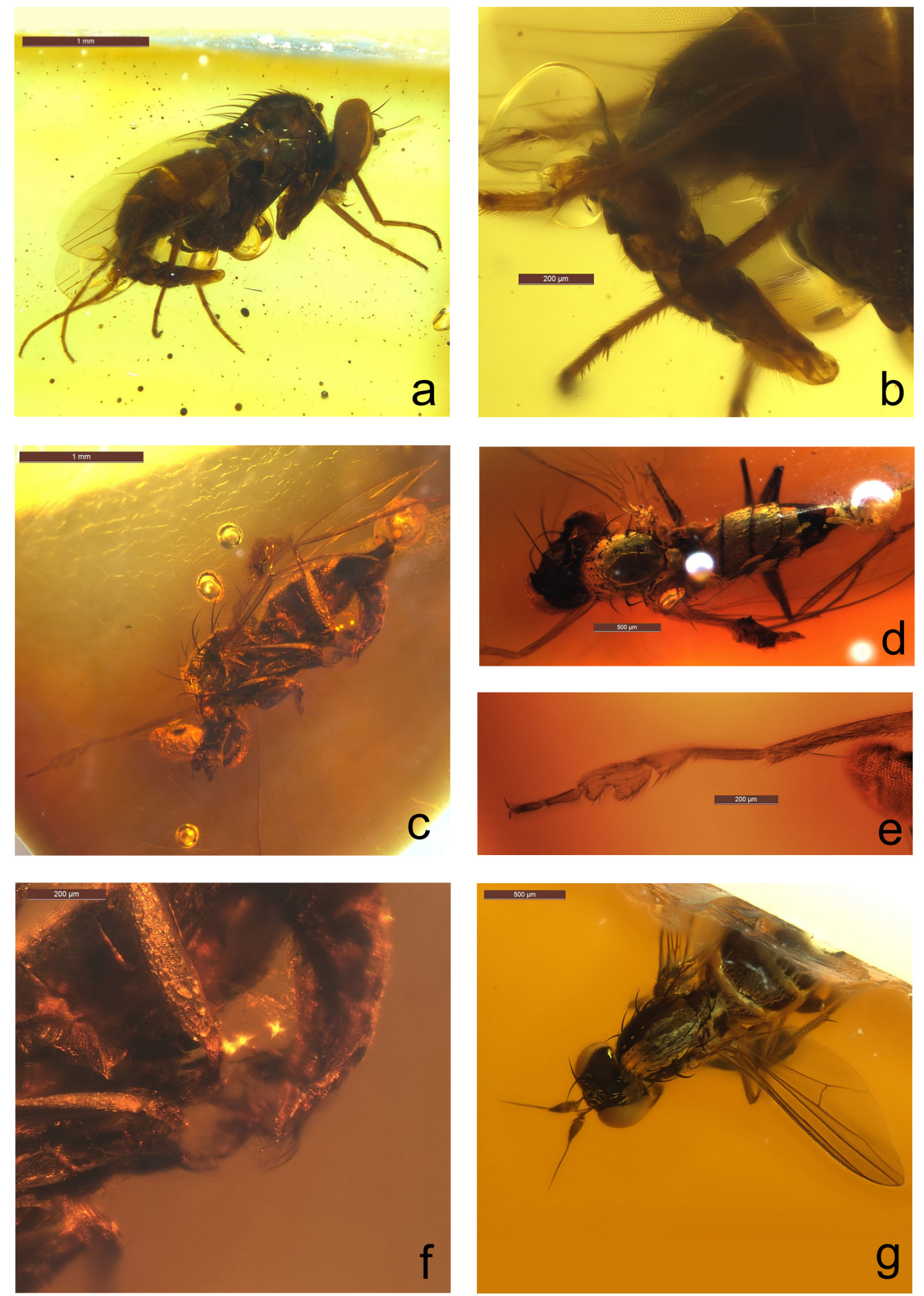

Figure 2. Medetera totolapa, sp. n.: a. male habitus, right lateral; b. hypopygium, right lateral. Medetera amissa sp. n.: c. male habitus, left lateral; d. male habitus dorsal; e. male tibia and tarsus I, dorsal; f. hypopygium, left lateral. Systenus sp.: g. female, habitus in part, dorsal.

Abdomen: metallic green with some bronze reflections; tergites 1-5 with short black setae along margins; tergite 6 not retracted; segment 7 from peduncle for hypopygium; sternite 8 dark brown; hypopygium (Fig. 2b) brown, with yellow cercus; hypopygium elongate, tapering; hypandrium arising at base of epandrium and narrow, elongate, extending almost to apex of surstylus; surstylus with apex circular, lobate; cercus short with fine yellow hairs.

Female. Unknown.

Remarks. Medetera totolapa is known from two males 
in the same amber piece. Although this species cannot be placed within any Medetera species group, potential diagnostic characters for this species would include the almost circular apex of the surstylus.

Etymology. The specific epithet totolapa is a place name in Chiapas and should be regarded as a noun in apposition.

\section{Subfamily PELOROPEODINAE}

Remarks. The subfamily Peloropeodinae was erected by Robinson (1970) for a number of small sized genera that mostly share a flattened posterior mesonotum, veins $\mathrm{R}_{4+5}$ and $\mathrm{M}$ parallel, and with anterior preapical setae present on femora II and III. However, the male postabdomen of the included genera show a wide range of structure, suggesting the subfamily is a heterogeneous assemblage.

\section{Genus PELOROPEODES Wheeler}

Remarks. This genus of rather small-sized flies has the uniseriate acrostichal setae and a characteristic swollen and globular hypopygium that is encapsulated by the preceding abdominal segments (e.g. Fig. 3c). There are 14 described recent Neotropical species but the fauna is much richer.

Peloropeodes paleomexicana Bickel, n. sp.

Type material. Amber specimen from Simojovel, Chiapas, Mexico. Holotype, ô, \#B-8425-151, Figs 3a-c) (UCMP).

Description. Male. Length $1.9 \mathrm{~mm}$; wing 1.7 x 0.7 (Figs 3a, 3b)

Head: dorsal postcranium flat; setae black; dorsal postorbital setae black, and as single row with dorsalmost seta posteriad of ocellar tubercle longer, and postorbitals in ventral half weaker and whitish; strong pairs of proclinate and converging vertical and diverging ocellar setae present; face only slightly narrowed below antennae, and sides subparallel along length; clypeus distinct; eye with facets relatively uniform; palp black, ovate, with black apical seta; proboscis yellowish; antenna brown; scape short, bare; pedicel only slightly longer than scape with only short setae; first flagellomere triangular, about twice as long as basal width, and apically pointed, arista dorsal, slightly longer than head height.

Thorax: dark brown with metallic green reflections; posterior mesonotum distinctly flattened and slightly depressed; setae black; ac uniseriate; 5 strong dc setae present, decreasing in size anteriorly; 1 posterior supra-alar seta, 2 post-sutural intra-alar setae, 2 presutural intra-alar seta, 1 postpronotal seta, 2 notopleural setae, subequal; scutellum with strong median seta and short weaker lateral seta.

Legs: coxae mostly dark brown, but yellowish distally; femora yellowish, and tibiae and tarsi yellow; CI and CII with short brownish anterior setae; CIII with strong black lateral seta near $1 / 3 ; \mathrm{I}: 1.7 ; 1.8 ; 0.9 / 0.6 / 0.4 / 0.3 / 0.3$; leg I without major setae and tarsal claws subequal; II: $2.8 ; 2.3$; $1.2 / 0.6 / 0.5 / 0.3 / 0.3$; FII with strong anterior preapical seta at $7 / 8$, otherwise bare; TII with distinct ad seta at $1 / 6$ (strong) and $2 / 3$ (weaker), with very short dorsal seta at $1 / 6$ and $2 / 3$, and with strong subapical ad, av and ventral seta; III: 2.7 ; $2.8 ; 0.7 / 0.9 / 0.7 / 0.5 / 0.4 ;$ FIII with strong anterior preapical seta at $7 / 8$, otherwise bare; TIII with strong ad seta at $2 / 5$, strong pd near $1 / 2$, strong dorsal at $9 / 10$, and with subapical ad and ventral seta.

Wing: hyaline; $\mathrm{R}_{2+3}$ joining costa near $7 / 8 ; \mathrm{R}_{4+5}$ and $\mathrm{M}$ parallel beyond level of $\mathrm{dm}-\mathrm{cu}$ crossvein, with $\mathrm{M}$ joining costa just posteriad of wing apex; $\mathrm{CuAx}$ ratio: 0.3 ; lower calypter pale yellow with fan of brown setae; halter yellow.

Abdomen: dark metallic green with some bronze reflections; tergites 1-5 with short black vestiture and row of longer setae along posterior margin; sternite 4 enlarged, hood-like over distal hypopygial appendages when hypopygium retracted; tergites 6 and 7 not visible; sternite 8 forming cap over left basal epandrium; hypopygium (Fig. 3c) brown, with yellow cercus; epandrium rounded, barrel-like; hypandrium arising at base of epandrium and broad, subrectangular with apical lunate indentation; phallus slightly longer than hypandrium; cylindrical epandrial lobe visible, bearing short apical seta; surstylus as short truncate projection, with narrow digitiform projection dorsally; cercus short and retracted between surstyli and with fine yellow hairs.

Female. Unknown.

Remarks. Peloropeodes paleomexicana is described here form a single male in Chiapas amber.

It is congeneric with recent species and has the greatly swollen hypopygium with short subrectangular surstylus. Although a number of recent Mesoamerican species have various leg MSSC (ventral setae on femur I, enlarged claw on tarsomere 5 of leg I), this species appears to lack any such modifications.

Etymology. The specific epithet "paleomexicana" refers to the presence of this genus in the ancient Mexican fauna.

\section{Subfamily SYMPYCNINAE}

Remarks. The subfamily Sympycninae is possibly the most complex in the Dolichopodidae, dominated by the large poorly-defined genus Sympycnus, There is a huge undescribed fauna with a predominately Southern Hemisphere distribution.

\section{Genus NEOPARENTIA Robinson}

Neoparentia chiapensis Bickel, n. sp.

Type material. Amber specimen from Chiapas, Mexico. Holotype, $\widehat{\jmath}$, \#Mx 210, Figs 4a-c, specimen somewhat distorted (SMNS).

Description. Male. Length: $\sim 2.1 \mathrm{~mm}$; wing 1.9 x 0.7 (Fig. 4a).

Head: dorsal postcranium flat; setae black; strong pairs 

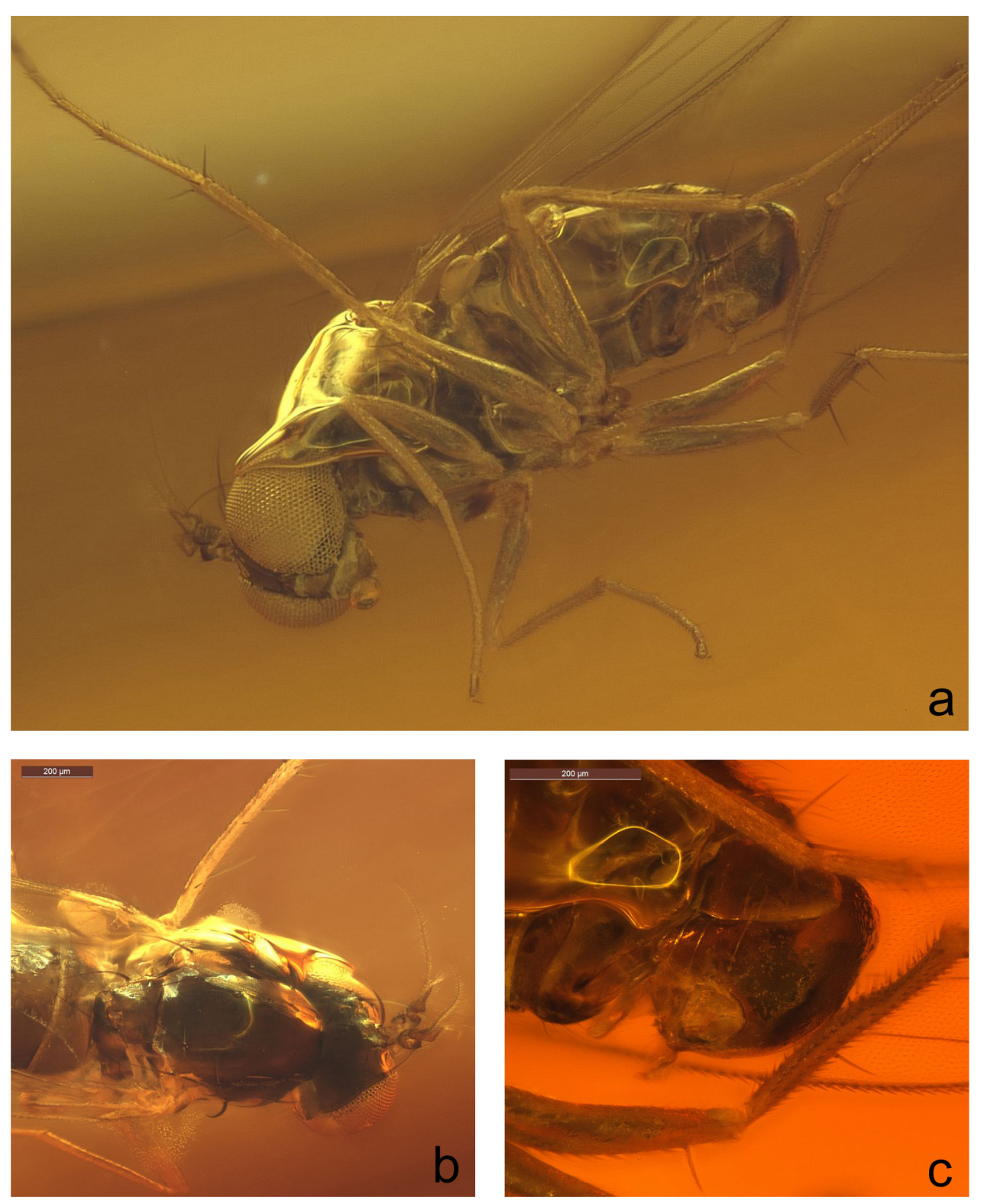

Figure 3. Peloropeodes paleomexicana, sp. n.: a. male habitus, left ventral; b. male head and thorax, dorsal; c. hypopygium, left lateral.

of converging vertical and diverging ocellar setae present; face only slightly narrowed below antennae, and sides subparallel along length; clypeus distinct; eye with facets relatively uniform; pulp yellow, ovate, with black apical seta; proboscis yellowish; antenna brown; scape short, bare; pedicel only slightly longer than scape, and with dorsoapical seta; first flagellomere as equilateral triangle, and apically pointed, arista dorsal, slightly longer than head height.

Thorax: dark brown and covered dorsally by brown pruinosity; posterior mesonotum not flattened (only apparently flattened anterior to scutellum due to distortion of specimen); setae black; single apparently irregular row of short ac present; 6 strong dc setae present, decreasing in size anteriorly; 1 posterior supra-alar seta, 2 post-sutural intra-alar setae, 2 presutural intra-alar seta, 1 postpronotal seta, 2 strong subequal notopleural setae; scutellum with strong median seta and short weak lateral seta.

Legs: coxae mostly dark brown, but yellowish distally; femora and tibiae apparently dark brown, and tarsi yellowish; CI and CII with black anterior setae; CIII with strong black lateral seta near $1 / 2 ;$ I: $1.9 ; 1.8 ; 0.8 / 0.4 / 0.3 /$ $0.3 / 0.2$; FI and TI without major setae; II: $2.8 ; 3.1 ; 1.2 /$ $0.6 / 0.5 / 0.3 / 0.3$; FII with strong anterior preapical seta at $7 / 8$; TII with strong ad seta at $1 / 5$ and $2 / 3$, and with circle of strong subapical pd ad, av and ventral seta; III: $2.8 ; 3.0$; $0.8 / 0.6 / 0.8 / 0.4 / 0.3$; FIII with strong anterior preapical seta at $7 / 8$, otherwise bare; TIII with strong ad ad seta at $1 / 4$, and with subapical ad and ventral seta. 

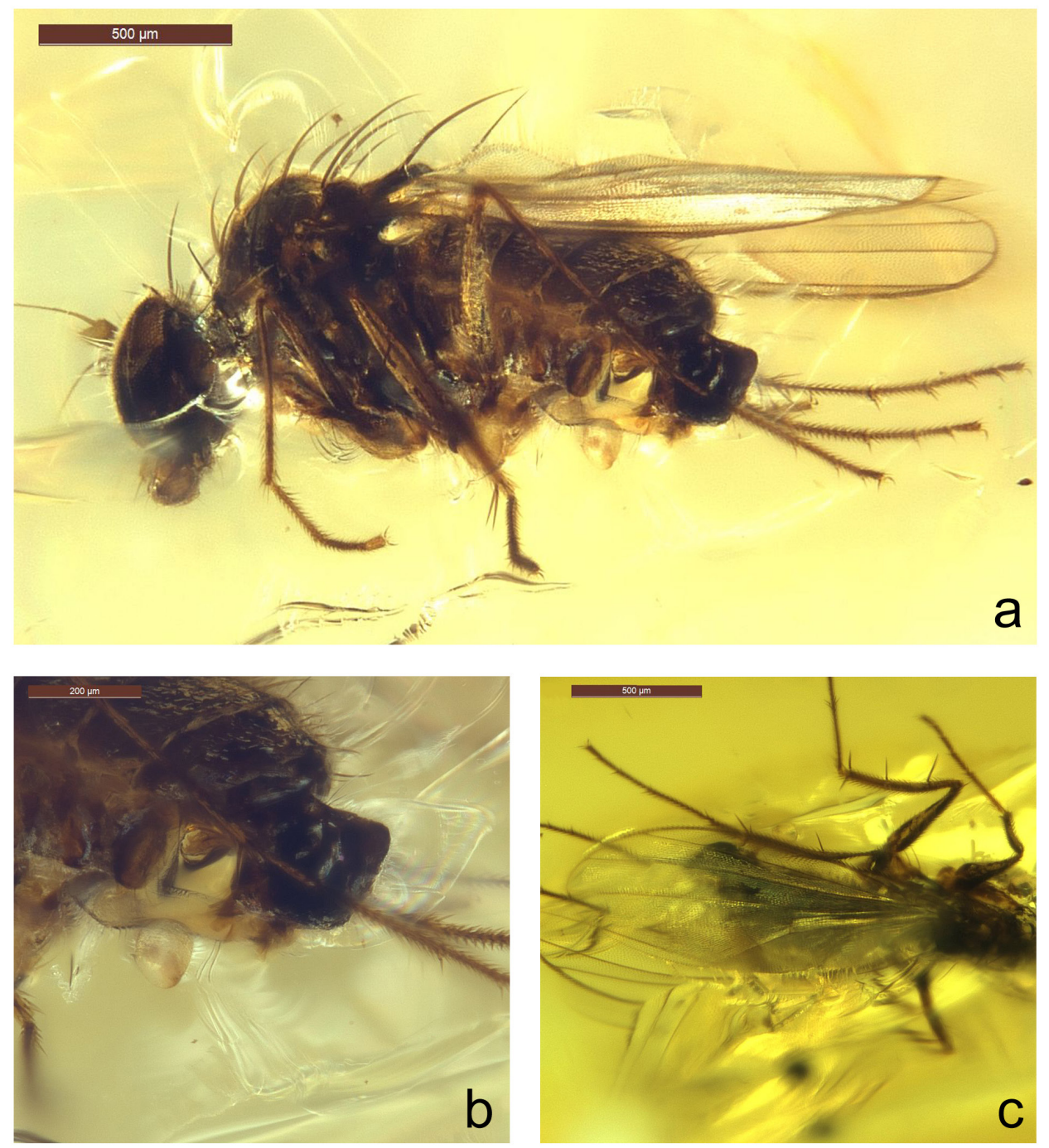

Figure 4. Neoparentia chiapensis sp. n.: a. male habitus, left lateral; b. hypopygium, left lateral; c. wing, dorsal.

Wing (Fig. 4c): hyaline; $\mathrm{R}_{2+3}$ joining costa near $7 / 8$; $\mathrm{R}_{4+5}$ and $\mathrm{M}$ subparallel beyond level of $\mathrm{dm}-\mathrm{cu}$ crossvein, with $\mathrm{M}$ joining costa just posteriad of wing apex; $\mathrm{CuAx}$ ratio: 0.3 ; lower calypter pale yellow with fan of brown setae; halter yellow.

Abdomen: apparently dark metallic green/ black; tergites 1-5 with short black vestiture and row of longer setae along posterior margin; sternite 8 forming cap over left basal epandrium; hypopygium brown, with yellow surstylus and cercus; epandrium rounded; hypandrium arising at base of epandrium; phallus tapering with apex curved, almost hooklike; epandrial lobe with short apical seta; surstylus short and truncate projection; cercus as longer tapering flagelliform projection extending to sternite 3 , and bearing short hairs.

Female. Unknown.

Remarks. This genus was erected by Robinson (1967) to accommodate a group of New World Sympycninae that has an elongate cercus and uniseriate row of acrostichal setae. Neoparentia chiapensis is described here from a single male in Chiapas amber. This species has the elongate cercus characteristic of the genus and fits the broad generic concept.

Etymology. The specific epithet chiapensis reflects its provenance in Chiapas, Mexico.

\section{Discussion}

This study was based on 37 pieces of Mexican amber with included specimens of Dolichopodidae (Table 1). Of these, 12 pieces were so obscured or damaged that only family level identification was possible. The remaining 25 pieces could be identified variously to the level of subfamily, genus, or species based on male characters (the six new species described in this paper).

Although a relatively small sample, one could conclude that little distinguishes this material from the modern 
Mesoamerican fauna. Not only do all the genera occur in the recent fauna, but three of the new species, Mesorhaga pseudolacrymans, Amblypsilopus monicae, and Medetera amissa can be closely associated with modern species and / or species groups. This suggests that many elements of the modern Neotropical dolichopodid fauna have been present at least since the Miocene.

\section{Acknowledgements}

We thank the following curators for the loan of specimens: G. Bechly (SMNS) and M. Goodwin (UCMP). The photographs were produced by J. Martin. Photoshop advice was provided by R. Hitchcock.

\section{References}

Bickel, D.J., 1994, The Australian Sciapodinae (Diptera: Dolichopodidae), with a review of the Oriental and Australasian faunas, and a world conspectus of the subfamily: Records of the Australian Museum, Supplement, 21, 1-394.

Bickel, D.J., 2007, The Mesoamerican Mesorhaga (Diptera: Dolichopodidae), with a taxonomic review of the New World fauna: Zootaxa, 1411, 47-67.

Bickel, D.J., 2009, Dolichopodidae (long-legged flies), in Brown, B.V., Borkent, A., Cumming, J.M., Wood, D.M., Woodley, N.E., Zumbado, M.A. (eds), Manual of Central American Diptera 1: Canada, Ottawa, NRC Research Press, 671-694.
Bickel, D.J., Arnaud, P.H., 2011, Medetera johnthomasi (Diptera: Dolichopodidae), a new species from California with notes on the aberrans species group: Pan-Pacific Entomologist, 87, 124-129.

Langenheim, J.H., 1967, Preliminary investigations of Hymenaea courbaril as resin producer: Journal Arnold Arborboretum, 48, 203-30.

McAlpine, J.F., 1981, Morphology and Terminology-Adults, in McAlpine, J.F., Peterson, B.V., Shewell, G.E., Teskey, H.J., Vockeroth, J.R., Wood, D.M. (Eds), Manual of Nearctic Diptera, Vol. 1: Canada, Ottawa, Research Branch Agriculture Monograph 27, 9-64.

Poinar, G.O., 1991, Hymenaea protera sp. n. (Leguminosae, Caesalpinioideae) from Dominican amber has African affinities: Experientia, 47, 1075-1082.

Poinar, Jr. G, Brown, A. 2002, Hymenaea mexicana sp. nov. (Leguminosae: Caesalpinioideae) from Mexican amber indicates Old World connections: Botanical Journal of the Linnean Society, 139(2), 125-132.

Robinson, H. 1967, Neoparentia, a new genus of American Dolichopodidae (Diptera): Proceedings of the Entomological Society of Washington, $69,252-259$

Robinson, H. 1970, The subfamilies of the family Dolichopodidae in North and South America (Diptera): Papeis Avulsos de Zoology, Sâo Paulo: 23(6), 53-62.

Solórzano Kraemer, M.M., 2007, Systematic, palaeoecology, and palaeobiogeography of the insect fauna from Mexican amber: Palaeontographica Abteilung A, 282, 1-133.

Solórzano Kraemer, M.M., 2010, Mexican amber, in Penney, D. (ed), Biodiversity of fossils in amber from the major world deposits: Manchester, UK, Siri Scientific Press, 42-56.

Manuscript received: January 16, 2015

Corrected manuscript received: April 13, 2015

Manuscript accepted: April 20, 2015 